\title{
A TRADUÇÃO PEDAGÓGICA: EXPERIMENTOS E EXERCÍCIOS PARA USO EM AULA
}

\author{
LA TRADUCCIÓN PEDAGÓGICA: \\ EXPERIMENTOS Y EJERCICIOS PARA USO EN CLASE
}

PEDAGOGIC TRANSLATION: EXPERIMENTS AND EXERCISES TO DO IN CLASS

Elisa Figueira de SOUZA CORRÊA ${ }^{1}$

RESUMO: Este artigo expõe experimentos e propostas de exercícios de tradução em aulas de língua não-materna (LNM) com objetivo de justificar e promover o uso da tradução pedagógica para fins de ensino-aprendizagem de LNM. Defende-se através dos exemplos apresentados que a tradução colabora para o aumento da consciência linguística do aluno e para o desenvolvimento de uma habilidade tradutória (ao menos em um grau mínimo), dentro de suas necessidades, para seu funcionamento social, fora da sala de aula. Essa consciência das peculiaridades necessárias para traduzir e um grau mínimo de proficiência ao fazê-lo são os pontos principais utilizados para sustentar a ideia de elevar a tradução a uma quinta habilidade basilar no ensino-aprendizagem de LNM, ao lado das quatro habilidades, já tradicionalmente aceitas, de ler, escrever, falar e compreender auditivamente na LNM.

PALAVRAS-CHAVE: Ensino-aprendizagem de língua não-materna. Tradução pedagógica. Tradução como quinta habilidade. Consciência linguística.

RESUMEN: Este artículo expone experimentos y propuestas de ejercicios de traducción en clases de lengua no materna (LNM) con el objetivo de justificar y promover el uso de la traducción pedagógica para fines de enseñanza-aprendizaje de LNM. Se defiende a través de los ejemplos presentados que la traducción colabora para el aumento de la conciencia lingüística del alumno y para el desarrollo de una habilidad traductora (al menos en un grado mínimo), dentro de sus necesidades, para su funcionamiento social, fuera de la sala de estar clases. Esta conciencia de las peculiaridades necesarias para traducir y un grado mínimo de competencia al hacerlo son los puntos principales utilizados para sostener la idea de elevar la traducción a una quinta habilidad basilar en la enseñanza-aprendizaje de LNM, al lado de las cuatro habilidades, ya tradicionalmente aceptadas, de leer, escribir, hablar y comprender auditivamente en la LNM.

\footnotetext{
${ }^{1}$ Universidade Estadual do Rio de Janeiro - (UERJ), Rio de Janeiro - Rio de Janeiro - Brasil. Professora do Instituto de Letras. Departamento de Letras Clássicas e Orientais. Doutora pela Pontifícia Universidade Católica do Rio de Janeiro - (PUC-Rio). E-mail: elisa.correa@uerj.br.
} 
PALABRAS CLAVE: Enseñanza-aprendizaje de lengua no materna. Traducción pedagógica. Traducción como quinta habilidad. Conciencia lingüística.

ABSTRACT: This paper reports several experiments and proposals of exercises that were done in non-native language classrooms. The objective is to justify and promote pedagogic translation use in non-native language teaching. By these examples, it is clear that translation helps to enhance student's language awareness and to develop a certain translation ability (i.e. a fifth skill) - which is essential in life beyond classroom.

KEYWORDS: Non-native language teaching. Pedagogic translation. Translation as a fifth skill. Language awareness.

\section{Introdução}

Este artigo trabalha com o conceito de "tradução pedagógica", entendido como o uso de exercícios de tradução com fins pedagógicos para o ensino-aprendizagem de língua não-materna ${ }^{2}$ (LNM), conforme a proposta inicial de Lavault (1985), refinada por Welker (2003). Para um funcionamento óptimo, a tradução pedagógica deve estar fundamentada em dois pilares: primeiramente, a compreensão de que não existe uma "tradução total, perfeita", mas sim que a tradução é uma "transformação regulada", conforme proposto em 1968 por Derrida (2001 apud FROTA, 2013, p. 4):

seria necessário substituir a noção de tradução pela de transformação: uma transformação regulada de uma língua por outra, de um texto por outro. Não se tratou, nem, na verdade, nunca se tratou de alguma espécie de "transporte", de uma língua à outra, ou no interior de uma única e mesma língua.

Essa concepção de tradução parte da visão de língua como um sistema heterogêneo de valores ligado a uma comunidade específica. Esse sistema complexo, dinâmico, aberto e heterogêneo, totalmente imbricado com formações ideológicas e circunstâncias históricas permite que estudiosos da tradução passem a trabalhar com diferenças muito mais sutis de natureza sociocultural e de contexto, conforme a situação tradutória (SOUZA CORRÊA, 2014, p. 29). Com isso, é possível aceitar melhor

${ }^{2}$ Utilizo esta denominação para fugir à diferenciação por vezes marcada entre língua estrangeira (LE) e segunda língua (L2). 
diferenças nas diferentes traduções de um mesmo texto - fugindo ao binarismo do certo/errado, mas também sem partir para um "vale-tudo".

Em segundo lugar, cremos que é crucial reconhecer a importância fundamental de certo grau de habilidade tradutória na vida de um aprendiz de uma LNM. Foi este reconhecimento que levou autores como Naimushin (2002, p. 47) a propor a elevação da tradução ao status de "quinta habilidade", ao lado das mais tradicionais habilidades de ler, escrever, falar e compreender auditivamente na LNM. A tradução como uma quinta habilidade, portanto, difere da formação de tradutores profissionais, mas pretende fazer notar ao aprendiz as peculiaridades necessárias para se traduzir e também um grau mínimo de proficiência ao fazê-lo, o qual pode ser mais ou menos ampliado conforme as necessidades e interesses de cada aluno. Como notou Naimushin (2002, p. 47), raramente aprendemos uma língua estrangeira com o fim único de nos comunicarmos exclusivamente nessa língua. Seja no trabalho, em família, com amigos, ou num nível pessoal informal, é comum que um estudante de uma LNM sinta necessidade de traduzir com maior ou menor grau de refinamento. Portanto, essa necessidade deve ser reconhecida por professores e profissionais do ensino-aprendizagem de LNM.

Alguns autores como Santoro (2011) são contrários a essa ideia da "tradução como quinta habilidade". Santoro (2011, p. 157) argumenta, por exemplo, que "é claro que as habilidades são muito mais do que apenas quatro" e que seria mais profícuo "no âmbito das reflexões sobre o ensino de línguas estrangeiras, pensar na tradução como parte das atividades previstas". No entanto, creio que atualmente estamos longe de nos afastarmos completamente de modelos de ensino-aprendizagem baseados nas "quatro habilidades", como é visível no cada vez mais vastamente utilizado "Quadro Europeu Comum de Referência para Línguas”, estabelecido em 2001. Sendo assim, por ora, parece-me mais vantajosa a adoção do termo "quinta habilidade" com fins de valorização e reconhecimento do lugar da tradução entre atividades comunicativas da "vida real" dos aprendizes. Com isso, facilita-se a entrada da tradução entre os objetivos a serem almejados no ensino-aprendizagem de LNM, fato que considero vantajoso para esse processo.

Neste artigo, procurei identificar algumas propostas interessantes de como inserir adequadamente a tradução nas salas de aula, sem recair nos modelos do passado, valorizando as necessidades quotidianas e profissionais dos alunos e potencializando a 
sua capacidade de aprendizagem da LNM. Para tal, toma-se como base o cenário criado pela "condição pós-método", isto é, uma rejeição de um método único, perfeito, ideal de ensino de LNM. É basilar também a redefinição pós-estruturalista dos conceitos de língua e de tradução, marcada por um afastamento do modelo platônico e do estruturalista, ambos crentes em uma tradução total.

O conceito de "condição pós-método" foi proposto nos anos de 1990 a partir, principalmente, dos trabalhos de quatro autores: Prabhu (1990), Allwright ([1991] 2003), Kumaravadivelu (1994), que cunhou esse termo, e Brown (1994). Em linhas gerais, esses autores concordam que é preciso libertar-se, primeiramente, da crença de que há um método ideal que irá suprir as necessidades de todo aluno/professor no ensino-aprendizagem de LNM. Alternativamente, propõe-se mais atenção às necessidades de cada aluno e/ou de cada turma e que o professor também se mantenha em constante reflexão sobre suas aulas.

Esse novo cenário, defendido por esses autores e seus correligionários desde o fim do século passado, permite que os exercícios de tradução sejam mais uma ferramenta à disposição do professor e que, desenvolvida, a capacidade de bem traduzir de/para a sua língua materna (LM) a língua estudada se torne uma quinta habilidade a ser almejada pelos alunos.

\section{Tradução de textos escritos}

A tradução escrita de textos inteiros, longos ou curtos, é provavelmente o exercício mais proposto hoje, justamente porque, dentro do quadro de rejeição ao chamado método da gramática e tradução (MGT) que se configurou na virada do século XIX para XX, os exercícios de tradução começaram a ser repensados como uma prática duplamente contextualizada, pois ocorre dentro do contexto da sala de aula e dentro do contexto textual - em oposição aos fragmentos de frases ou frases isoladas daquele método. Pontes, Lima e Sousa \& Silva (2015) reconhecem também tal reconhecimento por parte da comunidade acadêmica de estudos sobre a influencia do MGT na má fama da tradução pedagógica e sua retomada nas últimas décadas.

Klein-Braley \& Franklin (1998, p. 54) defendem que o ideal é começar a atividade com exercícios de tradução no sentido da LNM para a LM, pois há menos 
problemas linguísticos com que se preocupar nesse caso, já que a proficiência em LM é sempre muito maior que em LNM e, por isso, é mais fácil fazer os ajustes necessários. Os autores bem lembraram que, após o processo da tradução em si, o qual cuida sobretudo da qualidade tradutória, é preciso ajustar o texto para obter qualidade textual, isto é, fazer do texto traduzido, da tradução como produto, um texto fluente na LM.

Outra proposta interessante é a de Naimushin (2002, p. 48-49), que sugere fazerse, antes do início do exercício tradutório, um debate sobre qual será o tipo de texto produzido, a partir de qual estratégia tradutória, para que os alunos atentem e selecionem as informações do texto-fonte mais adequadamente:

Antes do exercício em si, normalmente reservo um tempo para conversar com os estudantes sobre os diferentes tipos de tradução e ter certeza de que eles entenderam completamente o propósito do exercício e que ganharam uma ideia dos pressupostos básicos da teoria da tradução. (NAIMUSHIN, 2002, p. 48). ${ }^{3}$

O tradutor precisa saber de onde vem e para onde vai o texto, quais os efeitos pretendidos etc. para poder fazer suas escolhas de forma adequada e mais consciente.

Assim, ampliar as possibilidades de concretização da atividade tradutória através da exploração do que pode ou não funcionar como um texto traduzido aceitável pelos leitores pretendidos permite que exercícios de tradução de textos sejam utilizados em todos os níveis de proficiência em LNM.

Reconhecendo a tradução como uma "necessidade no mundo real", a professora de inglês-LE, Silva (2007, p. 163), também propôs exercícios de tradução a suas turmas, embora percebesse que a maioria dos alunos, "por limitações linguísticas e culturais, muitas vezes, têm dificuldade em estabelecer o significado de palavras, frases e expressões dentro de um contexto social, cultural e até mesmo textual”. Não obstante, Silva acredita que é justamente como uma solução para essas limitações que a tradução surge. De fato, por ser precedida de uma leitura atenta (é voz corrente que os tradutores são os melhores leitores), a tradução proporciona uma oportunidade de interpretação e crítica aprofundadas do texto-fonte, de seu contexto (sua função, propósito etc.), assim

\footnotetext{
${ }^{3}$ Esta e as demais traduções deste texto são minhas, exceto quando indicado em contrário, acrescentando o original nos rodapés: "Before the actual exercise, I usually take time to talk with the students about the different types of translation and to make sure they fully understand the purpose of the exercise and gain some insight into the basic assumptions of the theory of translation".
} 
como uma melhor observação da estrutura do texto e das características tipológicas das línguas envolvidas.

Desse modo, Silva (2007, p. 165) propôs a seus alunos adolescentes de um curso de inglês a tradução de livros de uma série paradidática, todos com histórias curtas. A partir da tarefa proposta, os alunos deveriam: (a) citar, no mínimo, cinco palavras ou expressões novas; (b) citar, no mínimo, duas semelhanças e duas diferenças percebidas (de qualquer natureza) entre a LM e a LNM; (c) citar uma característica da LNM observada através da tradução. Antes de começar a tarefa, Silva também esclareceu para os alunos que o texto de chegada deveria ser coerente, atraente, claro, com uma linguagem natural e com o foco num leitor que não tem acesso ao texto-fonte ou suas imagens.

A atividade foi feita na meia hora final das aulas, durante várias aulas até que se completasse a tarefa. Silva percebeu crescente motivação e engajamento nos alunos, que levantaram questões interessantes como: "quais palavras são nomes próprios e quais não são? É preciso traduzir os nomes próprios ou não? Qual a relação do título com a história?" - e ao final de uma das aulas uma aluna comentou: "percebi que a gente não pode traduzir palavra por palavra" (SILVA, 2007, p. 166).

Através do relato de Silva, podem-se ver confirmadas diversas das vantagens da tradução pedagógica, desde a motivação e envolvimento participativo dos alunos em sala de aula - e em casa, já que um grupo "adiantava o dever", deixando para fazer em sala apenas a discussão de qual ou quais das traduções feitas seria(m) a(s) mais adequada(s) -, até a concretização de estratégias de aprendizado importantes, como a ativação heurística (alunos descobrem sozinhos características das línguas), estímulo da consciência linguística, da autonomia de aprendizado etc.

Em outro exemplo, DePaula (2007) relata que costuma traduzir com seus alunos do curso de graduação o livro A Brazilian adventure, um relato de viagem do jornalista inglês Peter Fleming. Por se passar no Brasil - mas sob olhar estrangeiro -, ela afirma que o livro "[proporciona] inúmeras ocasiões para se discutirem questões mais relacionadas aos aspectos culturais [e] também é extremamente rico em exemplificações de expressões idiomáticas e convencionais, tanto das mais transparentes quanto das mais opacas" (DEPAULA, 2007, p. 91). Nesse sentido, a proposta de DePaula parece ir ao encontro das estratégias que se preocupam em fazer com que o ensino-aprendizagem 
seja social e culturalmente relevante para os alunos, além de permitir que tragam suas próprias experiências e conhecimentos de mundo para a sala de aula com mais facilidade.

Além disso, percebe-se que o tipo de exercício proposto por DePaula também proporciona aos alunos um treinamento inicial em técnicas de tradução, pois é unânime entre estudiosos da tradução que, mesmo num âmbito amador, técnicas de tradução demandam treinamento, de modo que, para cumprir o objetivo de desenvolvimento dessa quinta habilidade, exercícios desse tipo são cruciais. Assim, DePaula (2007, p. 967) pede aos alunos para: (a) fazer uma previsão dos problemas que o texto pode trazer ao tradutor; (b) relacionar os problemas que de fato foram encontrados; (c) analisar as soluções; (d) verificar as soluções; (e) comparar com "outra estilística"; (f) discutir as diferentes soluções; (g) escrever sobre o processo tradutório.

Sem dúvida, tarefas como essas são ainda mais enriquecidas caso acompanhadas de discussões sobre as diferentes visões ou concepções de tradução (e de língua), no sentido de deixar claro o que é possível e o que se pretende atingir através da tradução.

Atkinson (1993, p. 62-5) também elaborou propostas de atividades de tradução de textos a serem utilizadas em sala de aula. A primeira propõe a tradução de um texto ou diálogo artificial que aborde temas e pontos de gramática abordados nas aulas recentemente. Note-se que, embora muitos educadores (de hoje e do passado) sejam contra o uso de textos artificiais, essa "artificialidade" é relativa, pois, na verdade, tratase de um gênero textual de contexto bastante claro, facilitando o trabalho de aluno e professor. Atkinson reforça que o professor sempre deve prover uma quantidade suficiente de detalhes acerca do contexto para que os alunos possam traduzir adequadamente, informando, por exemplo, qual o público-alvo (idade, gênero...), a situação (formal, informal) etc. Outras duas atividades são a comparação de traduções diferentes de um mesmo texto escritas pelo próprio professor ou, alternativamente, a comparação entre as traduções feitas pelos próprios alunos. A quarta proposta sugere a tradução "resumida" de um texto ou livro ou material de áudio, isto é, que os alunos leiam/ouçam e traduzam resumidamente em, por exemplo, um parágrafo, oralmente ou por escrito, o que foi compreendido. Atkinson (1993, p. 64) lembra que esse é realmente um tipo de atividade bem próxima do uso "na vida real" de uma LNM. 
Segundo Saito (2012), tradicionalmente, o ensino-aprendizagem de LNM no Japão faz uso de um método chamado yakudoku ("ler traduzindo"), o qual diferencia do MGT europeu:

Yakudoku, o método tradicional japonês de ensino-aprendizagem de inglês através da tradução, que foi erroneamente igualado ao MGT, veio da antiga tradição de fazer a exegese de passagens chinesas e, depois, holandesas e inglesas em japonês e que pode ser mais adequadamente explicado como uma mistura de classificação gramatical, análise sintática, interpretação e tradução. Dada sua inclinação original, esse método usa materiais linguísticos que são focados no conteúdo, autênticos (ainda que o método possa ser usado para explicar materiais artificiais) e, o mais importante, contextualizados. (SAITO, 2012, p. 30, grifos meus). ${ }^{4}$

Conforme Saito (2012, p. 30-1) afirma, então, através desse método, o professor explica os significados, analisa morfossintaticamente, interpreta e traduz um texto em conjunto com a turma. Assim, no exemplo dado em seu artigo, os alunos ouvem uma entrevista em inglês, em seguida, o professor faz a atividade de yakudoku e, por fim, ouve-se novamente a entrevista, de modo que o yakudoku se torna uma atividade auxiliar à compreensão auditiva:

a análise sintática e a interpretação deveriam funcionar como uma instrução pré-atividade, cujo objetivo é ajudar os estudantes a concentrarem-se na compreensão auditiva, em vez de ser uma análise discursiva autossuficiente, para ser decorada. (SAITO, 2012, p. 32)..$^{5}$

Para que se tenha uma ideia de como é o método yakudoku, transcrevo as primeiras linhas do exemplo dado por Saito em seu artigo. O comentário abaixo é apenas sobre a primeira frase da entrevista ouvida - "Os argumentos em favor dela [a tradução] como um meio de aprender uma língua [são que] ela encoraja acuidade e

4 "Yakudoku, the traditional Japanese method of teaching and learning English through translation, which has been wrongly identified with the GTM, [...] came from the old tradition of expounding Chinese passages and later Dutch and English passages in Japanese and can be more appropriately explained as a mixture of construing, parsing, interpretation and translation. Because of its original orientation, it uses language materials which are content-oriented, authentic (though the method can also be used for explaining inauthentic materials), and, most importantly, contextualized."

5 "Parsing-interpretation should work as pre-activity instruction whose aim is to help students to focus on listening comprehension rather than as a self-sufficient discourse analysis to be remembered. Although the main target for yakudoku has been reading materials, my example above possibly suggests that this method is flexible enough to serve the needs of various supplementary classroom activities." 
encoraja autoconfiança" (inserções de Saito) ${ }^{6}$-, embora o professor siga analisando com a turma, em japonês-LM, toda a fala do entrevistado (abaixo cito a tradução em inglês, do próprio Saito):

\begin{abstract}
Nesta parte, ele [o entrevistado] fala sobre o primeiro mérito da tradução no ensino de línguas. "Os argumentos em favor dela" significa literalmente その味方をする議論. O sintagma “em favor de alguma coisa", que pode ser parafraseado como 何々に味方して、何々に賛成の, vale a pena ser lembrado. Então, “Os argumentos em favor dela", onde "dela" (それ) refere-se à "tradução" (翻訳), significa それを良しとする翻訳. O próximo sintagma “como um meio de aprender uma língua”, significando 語学学習法としての, fornece uma informação adicional sobre o "dela" precedente. "Meio" [means, em inglês] é um substantivo que significa 手段, 方法 e é usado, lembrem-se, seja como substantivo singular ou plural, sempre terminando com "s". Nesse contexto, o substantivo é singular, precedido por um artigo indefinido... (SAITO, 2012, p. 31) ${ }^{7}$.
\end{abstract}

Saito (2012, p. 32-33) nota ainda que, a partir dessa atividade, outras podem ser propostas - desde que o professor creia que o texto em LNM foi de fato compreendido (e.g. leitura em voz alta do texto-fonte, teste da compreensão, discussão do conteúdo, redação sobre o texto-fonte etc.).

Benson (2000), também professor de inglês-LNM para japoneses, sugere a recuperação do exercício de "dupla tradução" (double translation). Segundo ele, embora seja uma técnica antiga da Idade Média, ainda é interessante. Basicamente, no exercício de dupla tradução, o professor pede aos alunos que traduzam um texto curto da LNM para sua LM. Após algum tempo (um dia, uma semana...), devolve o texto em LM e pede aos alunos que o traduzam de volta para a LNM. Terminada a nova tradução, os alunos passam a comparar os dois textos na LNM (original e retraduzido) e a avaliar o resultado, observando problemas de vocabulário e estrutura. Esse exercício também

\footnotetext{
6 "Arguments in favour of it [translation] as a means of learning a language [are that] it encourages accuracy and it encourages confidence."

7 "In this part, he [the interviewee] talks about the first merit of translation in language learning. 'Arguments in favour of it' literally means その味方をする議論. The phrase 'in favour of something', which can be paraphrased as 何々に味方して、何々に賛成の，is worth remembering. So, 'Arguments in favour of it', where 'it' (それ) refers to 'translation' (翻訳), means それを良しとする議論. The next phrase ‘as a means of learning a language', meaning 語学 学習法としての, gives an additional piece of information concerning the preceding 'it'. 'Means' is a noun which means 手段, 方法 and is used, you need to remember, as a singular or plural noun, always ending with ' $\mathrm{s}$ '. In this context, the noun is singular, preceded by an indefinite article..."
} 
serve para os alunos atentarem para as dificuldades de se traduzir tanto da, quanto para a LNM.

\title{
Tradução de frases isoladas
}

Como se começou a discutir na seção anterior, atualmente o uso de exercícios de tradução tem sido mais aceito apenas quando ligado a textos inteiros, para se enfatizar a importância do contexto e evitar exercícios tradutórios de frases isoladas, como os do MGT. Naturalmente, o retorno do antigo método não é algo desejável, mas alguns autores (WELKER, 2003; PETROVA, 2011) defendem que as frases isoladas ainda têm seu lugar, especialmente no caso de alunos iniciantes.

Como exemplo, pode-se ler o artigo de Petrova (2011) em que ela descreve as diversas dificuldades que enfrentam os estudantes russos de português. Para superar essas dificuldades, Petrova defende não apenas o uso da LM em sala de aula, como também explica que, no primeiro contato dos alunos com essa nova língua, a comparação gramatical é imprescindível e, ao explicar como ocorre o ensino em sua universidade em Moscou, logo se reconhecem técnicas bastante tradicionais:

\begin{abstract}
nas primeiras aulas, explicando a estrutura da frase portuguesa, recorre-se ao sistema casual existente em russo. A língua russa tem seis casos, daí, as relações casuais estarem incorporadas na mente dos alunos que têm, na sua maioria, uma boa preparação escolar. Por conseguinte, explicamos o significado das preposições mediante o sistema casual. Nas frases: A professora mostra Lisboa aos alunos no mapa. [...] A professora é sujeito no caso Nominativo (PETROVA, 2011, p. 3-4).
\end{abstract}

Ou seja, uma associação é feita entre o sistema de casos russo e a posição na frase e as preposições e os pronomes portugueses para que os alunos, então, consigam formar frases simples, do tipo "Ivo viu a uva" - exatamente como propunham os antigos manuais de MGT do fim do século XVIII.

Então, antes de fazer coro aos teóricos contrários ao MGT e condenar veementemente as práticas de Petrova e seus pares, julgo ser preciso refletir, nestes tempos de pós-método e de estímulo à consciência linguística, se não tem validade tal prática, especialmente, como reforça a professora russa, num primeiro momento do ensino: 
na etapa inicial do ensino-aprendizagem de línguas tipologicamente distantes não podemos rejeitar a explicação gramatical, porque as diferenças estruturais entre a língua materna e o português dificultam a produção oral e escrita e geram erros provenientes das diferenças linguísticas. (PETROVA, 2011, p. 4).

Acredito que não é possível, diferentemente do que afirma Petrova acima, atribuir somente à distância existente entre as duas línguas as dificuldades dos alunos e os erros cometidos por eles. Ainda assim, tal diferença certamente contribui para isso, de forma que entendo que, em certo aspecto, mesmo similares ao MGT podem ter um lugar no ensino-aprendizagem hoje, isto é, na forma do aproveitamento da análise e da tradução de frases isoladas. Note-se também que frases isoladas e artificiais, uma vez trazidas para a sala de aula, perdem seu caráter de isolamento e artificialidade porque, dentro da sala de aula, passam a fazer parte daquele contexto, isto é, tornam-se parte do gênero textual "material didático", muito familiar a todo aluno. Enquanto o estudo de textos tem grandes vantagens para a compreensão de aspectos sociais, culturais e pragmáticos da LNM, o estudo de frases pode contribuir para o desenvolvimento de consciência linguística e para a compreensão da gramática básica da LNM, sendo especialmente útil, portanto, nos níveis iniciais.

Em minha experiência como professora de línguas muito distantes, esse foi o caso. Ao lecionar português para chineses, na Universidade de Hebei, um dos livros didáticos adotados propunha exercícios de tradução de expressões ou frases isoladas, todas com as estruturas simples vistas ao longo da lição. Tal exercício por vezes suscitava algumas discussões úteis, porque uma frase poderia ser traduzida de diferentes maneiras - justamente pela falta de contexto - permitindo reflexões linguísticas. Por exemplo: "Que dia é hoje?" pode ser “Jīntiān xīngqīijî?" (Que dia da semana é hoje?) ou “Jīntiān jǐháo?” (Que dia do mês é hoje?).

De forma semelhante, Atkinson (1993, p. 61) sugere como atividade em sala de aula que o professor ofereça frases mal traduzidas para serem corrigidas pelos alunos, especialmente frases cristalizadas, como "Que horas são?”, “Tem fogo?” etc., para que os alunos possam atentar para os problemas da tradução palavra por palavra. Com o tempo, é possível fazer o mesmo exercício com frases contendo pontos gramaticais dessemelhantes entre as línguas: para a frase original "Hace 2 años que vivo aquí" poderiam ser propostas as más traduções na LNM a serem corrigidas: "I live here since 2 years" / "It's 2 years that I am living here" (ATKINSON, 1993, p. 61). 
A grande vantagem desse tipo de exercício é sua simplicidade, que pode, creio, ser adaptada para turmas de qualquer nível, sem dificuldade. Embora não seja jamais suficiente se feito de forma exclusiva (e esse foi o maior erro do MGT), tal tipo de exercício pode ser um recurso muito útil ao professor e proveitoso para os alunos. $\mathrm{O}$ confronto direto com as diferenças entre duas línguas, que a tradução evidencia, pode ajudar o aluno a adquirir, com mais rapidez e intensidade, uma consciência não só linguística como, por vezes, sociocultural. Embora a brevidade dos exemplos acima possa não permitir, se considerarmos que as línguas são produtos sociais, mesmo a análise de expressões cristalizadas pode lançar luz sobre algumas características socioculturais, ideológicas etc. de um povo.

\section{Escrevendo em LNM via $\mathbf{L M}^{8}$}

Desde a década de 1990, Kobayashi e Rinnert (1992, 2009, 2012) vêm publicando uma série de estudos na área de ensino de redação em inglês-LNM via japonês-LM, através dos quais atestaram experiências positivas com o uso da tradução como um recurso intermediando a composição de textos na LNM, seja com alunos iniciantes ou de níveis avançados. Em seu experimento de 1992, as autoras submeteram seus alunos de graduação (divididos em nível alto e baixo de proficiência em inglês) a duas tarefas: deveriam escrever uma redação diretamente em inglês e outra em japonês, que, posteriormente, traduziriam para o inglês.

Com base nos diversos critérios de avaliação das redações "diretas" e "traduzidas", as pesquisadoras perceberam que, em termos de "qualidade do conteúdo", "organização do texto" e "estilo", os alunos de nível baixo se beneficiaram significativamente do uso da tradução, obtendo melhores notas nas redações traduzidas em $80 \%$ dos casos. Os alunos de nível alto também mostraram uma diferença para melhor, embora muito menor, mostrando em suas redações traduzidas vantagens apenas quanto ao vocabulário e estrutura das sentenças, não havendo grandes diferenças nos outros quesitos. Ainda assim, 70\% das redações traduzidas desses alunos de nível alto

8 A maioria dos estudos de ensino-aprendizagem de LNM não faz diferença entre a oposição tradução/versão, comum nos Estudos da Tradução. 
receberam notas melhores que suas redações diretas (KOBAYASHI; RINNERT, 1992, p. 207).

Num segundo momento dessa pesquisa, as autoras apresentaram novamente os textos em inglês (tanto os traduzidos quanto os diretos) aos alunos, sem as correções dos professores, e pediram que comentassem qual seria o melhor texto e por quê. Através dessas entrevistas, Kobayashi \& Rinnert (1992, p. 199; 207) puderam notar que, embora os alunos de nível baixo percebessem serem melhores os seus textos traduzidos, os alunos de nível alto preferiram os textos diretos, acreditando ser a redação direta "mais natural", com expressão "mais inglesa", melhor gramática etc. Acredito que essa percepção corrobora o quanto as crenças na sala de aula monolíngue foram absorvidas pelo senso comum, o que também pode ser visto pela afirmação dos alunos de que preferiam escrever diretamente para "aprender a pensar na LNM" (cf. KOBAYASHI; RINNERT, 1992, p. 200).

Esses achados estão em consonância aos de Saliés (1995a; 1995b), em uma pesquisa com estrangeiros de diversas nacionalidades estudando inglês nos EUA e, mais especificamente, em uma segunda pesquisa dirigida com dois estudantes malásios. Embora na primeira pesquisa de Saliés apenas três estudantes declaradamente indicassem preferir traduzir a escrever diretamente na LNM (SALIÉS, 1995a) - e os demais explicassem, assim como os japoneses supracitados, que preferiram pensar e escrever diretamente na L2 -, a pesquisadora brasileira percebeu através dos questionários aplicados que a LM era de fato utilizada por todos os alunos em sua escrita. Como nota Saliés (1995a):

os aprendizes usam a L1 para desempenhar operações cognitivas. Uma vez que a escrita está diretamente ligada ao letramento e a conhecimentos previamente existentes, os estudantes-escritores recorrem a "pensar na L1" ou a reconstruir conceitos por trás dos significados das palavras na L1 para usar aquele conhecimento. A língua materna, então, assume um papel facilitador, minorando bloqueios de memória (KERN, 1994) e permitindo a estudantesescritores internacionais explorar completamente ideias em seus próprios níveis cognitivos (KOBAYASHI, 1992). Os resultados das questões abertas reforçam essa visão completamente. ${ }^{9}$

9 "Learners use L1 to perform cognitive operations. Since writing is directly linked to literacy and previous existing knowledge, student writers resort to "thinking in L1" or reconstructing the concepts behind the meanings of words in L1 to use that knowledge. The native language then assumes a facilitative role, easing memory constraints (Kern, 1994) and allowing international student writers to 
Em sua segunda pesquisa, Saliés (1995b) conduziu três experimentos com dois estudantes malásios com características similares ${ }^{10}$, mas que declararam, durante a primeira pesquisa, proceder diferentemente quanto ao uso da LM na escrita em LNM: um afirmara não usar a LM nunca, enquanto o outro declarara que costumava traduzir "palavras, frases ou ideias difíceis" ou ainda que "pensava ou discutia sobre temas na LM” antes de escrever na LNM (SALIÉS, 1995b, p. 6). Apesar de sua declaração inicial, porém, o malaio que dizia não usar a LM retificou essa afirmação durante a segunda pesquisa, justificando que, embora não escrevesse na LM antes de escrever na LNM, ele, de fato, costumava pensar e até falar em voz alta na sua LM para organizar seu texto em LNM.

Assim, nessa segunda pesquisa, Saliés (1995b) acompanhou os dois estudantes malaios no processo de composição de três textos em inglês: o primeiro precedido por um exercício de pré-escrita em inglês, o segundo com pré-escrita em malaio e o terceiro com pré-escrita e escrita de um rascunho em malaio que, então, deveria ser traduzido para o inglês. Os textos finais eram, então, avaliados por professores em cinco quesitos: conteúdo, organização, estrutura frasal, vocabulário e "mecânica" (ortografia, pontuação, uso de maiúsculas e minúsculas e forma). Os resultados da pesquisa confirmaram as expectativas iniciais da pesquisadora de que o uso de uma pré-escrita em LM beneficia a produção textual, especialmente no tocante ao conteúdo e que o uso da tradução beneficia também no tocante à organização, vocabulário e gramática. Também ficou claro que os estudantes pensavam na LM 50\% do tempo para escrever em inglês-LNM.

Saliés (1995b, p. 24) constatou que ambos acreditavam (e almejavam) pensar apenas na LNM, mas pondera que, a despeito dessas crenças veiculadas pelos instrutores de inglês ao longo da vida dos estudantes, "pedir a eles para descartar o corpo de conhecimento que trazem para a aula via LM é o mesmo que pedir a estudantes-escritores adultos para esquecer a maior parte do que aprenderam ao logo da vida quando estão escrevendo"11. Sendo assim, a autora reivindica uma revisão do

fully explore ideas on their own cognitive levels (Kobayashi, 1992). Results of the open-ended questions fully reinforce this view."

${ }^{10}$ Ambos têm a mesma nacionalidade, LM, sexo, idade etc.

11 "Asking them to do away with the body of knowledge they bring to class via their NLs [native languages] is the same of asking competent adult-student writers to forget most of what they have learned in a lifetime when they are writing." 
ensino exclusivamente monolíngue em LNM, lembrando que o uso da LM permite que o texto se torne mais rico conceitualmente, de modo que, se o objetivo do ensinoaprendizagem de LNM é ensinar os alunos "a procurar por estruturas de conhecimento, combinar informações e a passar mensagens com sucesso, processar a informação na L1, interna e externamente, contribui muito para a escrita em L2" (SALIÉS, 1995b, p. $26)^{12}$.

Também é interessante observar como esse exercício de escrever primeiramente na LM permite aos alunos "analisar contrastivamente" as línguas envolvidas no exercício. Assim, Saliés (1995a) comenta que "em duas ocasiões, dois estudantes descreveram como a estrutura e o arranjo do chinês são diferentes [do inglês]. Um deles escreveu: 'em chinês, poucas palavras explicam uma coisa complexa, mas em inglês é difícil fazer isso. Então, quase sempre uso a palavra errada""13. Segundo Saliés (1995b, p. 14), o mesmo ocorre quando, na terceira etapa, os estudantes devem traduzir do malaio para o inglês, devido às grandes diferenças que percebem entre as duas línguas:

[eles estavam] desconfortáveis com a ideia de traduzir seu último ensaio do malaio para o inglês. De acordo com eles, era muito arriscado. Estavam certos de que o resultado final seria pior, por causa das diferenças entre o modo como se escreve em malaio e em inglês. [...] As maiores dificuldades de tradução que relataram eram relacionadas com concordância de tempo e ordem das palavras. ${ }^{14}$

Ainda assim, a pesquisadora orientou os dois rapazes a não traduzir palavra por palavra, mas sim "as ideias que estavam regendo o texto, as transições e organização das ideias. Em outras palavras, uma tradução idiomática. Já que não sei nada sobre a língua malaia, não pude ser de nenhuma ajuda na solução de problemas de tradução" (SALIÉS, 1995b, p. 14) ${ }^{15}$. É interessante notar que Saliés (1995b, p. 15) percebeu que

12 "To search for knowledge structures, combine information, and convey messages successfully, processing information in L1, internally and externally, contributes highly to L2 writing."

13 "In two instances, two students described how Chinese structure and arrangement are different [from English]. One of them wrote: 'in Chinese few words explain a complex thing, but in English, it's hard to do that. So, I almost always use the wrong word."'

14 "[They are] uneasy with the idea of translating their last essay from Malay to English. According to them, it was too risky. They were sure their final products would be worse because of the differences between the way one writes in Malay and in English. [...] The major translation difficulties they reported have to do with tense agreement and word order."

15 "Ideas that were controlling the text, the transitions, and organization of ideas. In other words, an idiomatic translation. Since I do not know anything about the Malay language, I could be of no help in trying to solve translation problems." 
parte da dificuldade de tradução de um dos estudantes estava no fato de ele não saber identificar categorias gramaticais e de insistir que o "malaio não tem gramática", no que considero um caso emblemático de como o desenvolvimento de uma consciência linguística pode auxiliar o estudo de LNM.

De qualquer modo, as três pesquisadoras - Saliés (1995a; 1995b) e Kobayashi \& Rinnert (1992) - coletaram opiniões dos alunos de que traduzir - independente de tornar o texto melhor ou não - é mais difícil do que escrever diretamente, mais trabalhoso e mais demorado, o que poderia ser visto como uma desvantagem desses exercícios. Em especial, diversos alunos declararam a dificuldade de encontrar as palavras certas quando há nuances no significado.

Como professora, contudo, considero tais observações sobre a dificuldade da tradução uma vantagem e, a meu favor, trago a declaração de um dos alunos japoneses de Kobayashi \& Rinnert (1992, p. 200):

um estudante mencionou a vantagem de ser capaz de adquirir vocabulário e estruturas em inglês pelo desafio da tradução, em vez de apoiar-se apenas em palavras e formas anteriormente conhecidas, assim defendendo o uso da escrita via tradução como uma estratégia de aprendizagem de línguas. ${ }^{16}$

Como bem percebeu esse aluno, através da tradução proporciona-se também um desafio de descoberta da estrutura interna do período, organização do texto, vocabulário novo etc. da LNM para não falar dos frequentes insights referentes à LM, trazidos pela relação de diferença (ou mesmo de similaridade) com a outra língua.

De fato, pesquisas recentes de Kobayashi \& Rinnert (2009; 2012) atestaram que o conhecimento linguístico sobre uma língua é utilizado em relação às outras, de modo que, por exemplo, conhecimento sobre organização textual e estilo discursivo em inglês-LNM foi, na pesquisa, por vezes transplantado para redações em japonês-LM, e vice-versa. Além disso, alunos que sabem mais de uma LNM tendem a fazer diversas comparações entre estas e sua LM e a associar seu conhecimento sobre cada uma delas. Assim, as autoras concluem que

16 "One student mentioned the advantage of being able to acquire English vocabulary and structure through the challenge of translation, rather than relying only on previously learned words and forms, thus advocating the use of writing through translation as a language learning strategy." 
as escolhas das características dos textos em L1/L2/L $3^{17}$ foram influenciadas por fatores previamente identificados: formação/experiência como escritor; percepções; proficiência linguística; assunto; e público-alvo. Ademais, dois novos fatores foram identificados: regência [...] e similaridade linguística percebida (e.g., japonês/coreano). (KOBAYASHI; RINNERT, 2012, p. 60). ${ }^{18}$

Ou seja, o grau de semelhança tipológica percebido pelos alunos entre as línguas sabidas serviu-lhes como instrumento na composição de seus textos. Assim, ao escrever em coreano, a aluna se sentiu mais à vontade para aproximar sua escrita do que sabia sobre a composição de textos em japonês, sua $\mathrm{LM}^{19}$; e o mesmo fez a aluna que sabia espanhol e percebia essa língua como sendo semelhante ao inglês.

\section{Tradução oral (interpretação)}

Nem sempre autores e livros didáticos fazem a diferenciação, comum no meio profissional, entre "tradução" e "interpretação", de forma que a maioria termina por falar em "exercícios de tradução oral”, e não em "exercícios de interpretação".

Atkinson (1993, p. 65) e Liberatti (2012, p. 185-6) são dois dos autores que propuseram atividades em que alunos de nível intermediário ou maior atuam intermediando a comunicação oral entre um falante da sua LM e outro da LNM em estudo. Embora mais complexa de ser executada, por demandar mais preparo do professor e dos alunos e também envolver a interação de vários alunos (ou o uso de gravações previamente preparadas), essa atividade também conta com a vantagem de ser próxima a possíveis usos da LNM na "vida real" dos alunos, fora das salas de aula, profissionalmente etc. e, portanto, tem apelo motivacional.

Duff (1994) defende que exercícios de tradução oral sejam a base do uso da tradução pedagógica, pois consomem menos tempo e não geram trabalho extra para o

${ }^{17}$ L1 é a língua materna. L2 é a primeira LNM aprendida pelo aluno (nessa pesquisa, sempre o inglês); L3 é a LNM que foi aprendida depois da L2 (nessa pesquisa, as autoras trabalharam com pessoas que tinham espanhol, francês e coreano como L3).

18 "Choices of L1/L2/L3 text features were influenced by previously identified factors: writing instruction/experience; perceptions; language proficiency; topic; and audience. In addition, two new factors were identified: regency [...] and perceived language similarity (e.g., Japanese/Korean).”

${ }^{19}$ Alguns linguistas defendem que coreano e japonês fazem parte da mesma família linguística, a família altaica. Mesmo que essa hipótese não se comprove, essas línguas têm, de fato, diversas semelhanças tipológicas. 
professor (i.e. correções de exercícios escritos). Além disso, ele também acredita que na tradução oral a "fluência" vem mais naturalmente à mente do aluno:

essas aberturas ou oportunidades na língua-alvo [i.e. fazer uso do potencial da L1 para ganhar clareza ou precisão] podem facilmente se perder. É por isso que enfatizo tanto a tradução oral e a comparação de anotações baseada na tradução oral. Muitas vezes, as melhores soluções ocorrem quando traduzimos de veneta. Não sem pensar, mas sem ponderar demais. (DUFF, 1994, p. 74). ${ }^{20}$

É importante notar que, com isso, ele não defende que se apressem os alunos em suas traduções ou que sejam feitas sem pensar, assim como acredita que as atividades de tradução nunca devem vir apenas com instruções do tipo "traduza isso" (o que muitas vezes é a realidade nos livros que contêm exercícios de tradução). Duff (1994, p. 8-9) defende a necessidade de se utilizarem exercícios de tradução regularmente, de modo bem planejado e com restrição de tempo para que os alunos possam adquirir essa habilidade. Além disso, enfatiza a necessidade da discussão sobre as traduções feitas:

em todas as atividades, tento manter um equilíbrio entre dar aos estudantes tempo demais para pensar e tempo de menos. A tradução constantemente envolve fazer escolhas. Quanto mais tempo você se senta sobre o muro, mais difícil é tomar uma decisão. Muitas vezes as melhores soluções ocorrem-nos depois de a ponderação ter sido feita e a decisão, tomada. A função da discussão, então, é dar aos estudantes, tempo para uma reflexão ulterior e a chance de mudar de ideia. (DUFF, 1994, p. 9). ${ }^{21}$

A grande maioria dos exercícios propostos por Duff (1994), em seu livro Translation, é voltada para uso em sala de aula, em grupo, muitos oralmente, utilizando pequenos trechos de textos ou frases com temas variados. Antes do exercício, o professor informa um contexto ou os alunos são levados a inferir ou construir o contexto, todos focando pontos específicos da matéria (sejam gramaticais, funcionais etc.). Assim, os alunos têm a oportunidade de trabalhar conjuntamente comparando,

20 "These target language openings or opportunities [i.e. making use of the potential of the L1 to gain clarity or precision] can easily be missed. This is why I have placed so much stress on oral translation and on comparison of notes based on the oral translation. Often, the best solutions occur when we translate off-the-cuff. Not without thinking, but without too much pondering."

21 "In all activities, I have tried to strike a balance between giving the students too much time to think, and too little. Translation constantly involves making choices. The longer you sit on the fence, the harder it is to make up your mind. Often the best solutions occur to us after the thinking has been done and a choice made. The function of the discussion, then, is to give the students time for further reflection, and a chance to change their minds." 
discutindo e respondendo às sugestões de seus pares sobre as melhores opções tradutórias.

\section{A tradução audiovisual (TAV) e outros recursos}

Santos Jr. (2009) sugere que um recurso motivador dos alunos é o uso de ferramentas colaborativas da Internet. Assim, ele tem-se dedicado a desenvolver projetos que envolvam seus alunos em atividades de interação com outros navegantes da Internet, especialmente falantes nativos da LNM estudada (no caso, o inglês), seja em tempo real ou não.

Nesse âmbito, Santos Jr. (2009, p. 18) afirma que uma ótima maneira de motivar os alunos a se engajarem nas atividades é envolvê-los na participação de projetos como, por exemplo, a tradução de verbetes para a Wikipédia ${ }^{22}$. Realmente, hoje, é gigantesca a quantidade de websites e documentos colaborativos online que, como a Wikipédia, são escritos, editados e traduzidos para outras línguas pelos próprios usuários da Rede.

Mais que isso, é visível também o ardor com que tais usuários se dedicam a essas atividades, em especial os que se agrupam em comunidades de fãs - muitas vezes já com intenção de realizar algum projeto de tradução. Assim, nasceram, por exemplo, as comunidades de "fansubs", isto é, comunidades que se dedicam a traduzir e legendar vídeos de gêneros variados (cf. SOUZA CORRÊA, 2016). Concordo, então, com Santos Jr. (2009, p. 18), que atividades como "a legendagem de filmes, videoclipes e outros textos autênticos para disponibilização online" têm grande sucesso motivacional entre alunos atualmente.

Atividades que propusessem a tradução de textos menos convencionais, como as histórias em quadrinho ou os videogames provavelmente teriam o mesmo sucesso. Uma possibilidade a se explorar, por exemplo, são as obras dos scanlators $^{23}$ das quais o professor poderia utilizar-se facilmente, como alternativa à atividade acima.

Outra possibilidade é apresentada por Sousa (2004, p. 53), defensora de atividades de TAV no ensino-aprendizagem de LNM. Ela observa que esse recurso

${ }^{22}$ Enciclopédia online colaborativa, na qual qualquer pessoa pode acrescentar ou editar verbetes.

${ }^{23}$ Palavra formada da junção de scan (digitalizar) e translator (tradutor), para se referir aos fãs que, gratuitamente, digitalizam e traduzem mangás japoneses, deixando-os disponíveis para outros fãs na Internet. 
começou a ser notado pelos teóricos quando se percebeu que muitos imigrantes se utilizavam das legendas ocultas (originalmente voltadas para surdos) para aprenderem melhor a língua do país em que viviam. Com base em pesquisas, descobriu-se que o uso simultâneo de imagem, som e texto proporciona um contexto enriquecido semanticamente, de modo que "a apresentação multissensorial da informação facilita o aprendizado de novas palavras e conceitos. Os alunos também se beneficiam com o fato de verem a grafia das palavras vocalizadas e de não terem que se preocupar com sotaques e pronúncia” (SOUSA, 2004, p. 53).

Além disso, uma pesquisa finlandesa (cf. VANDERPLANK, 1988 apud SOUSA, 2004) sobre o uso de filmes legendados em sala de aula comprovou que, sejam legendas em LM ou em LNM, os alunos sempre se beneficiam desse recurso, pois ficam mais atentos às palavras desconhecidas. Também é fato que "os filmes trazem à sala de aula mais variedades de falas autênticas, difíceis de serem encontradas em materiais didáticos" (SOUSA, 2004, p. 56), diversificando tanto a exposição linguística quanto cultural dos alunos na LNM.

Pensando nisso, Sousa (2004, p. 58 et seq.) traz uma proposta de atividade com TAV na qual o professor pode levar a seus alunos uma cena de filme para ser traduzida. Sousa nota que, por sua complexidade, esse tipo de atividade é mais indicado para níveis intermediários ou avançados e que, ainda assim, algumas atividades prévias são recomendadas (e.g. leitura de uma sinopse, apresentação de lista de vocabulário) para que os alunos se sintam mais confortáveis e seguros de entender a cena. Só então o professor prosseguiria apresentando-a primeiro sem legendas, em seguida com legendas na LNM e só depois partiriam para a tradução das legendas, com os alunos divididos em grupos. Diversas atividades também podem ser feitas após a realização da tradução, como discussão sobre o vocabulário, sobre as traduções feitas, reencenação da mesma cena pelos alunos etc.

Dessa forma, a TAV torna-se um recurso valioso para o professor de hoje. Se a simples utilização de vídeos legendados na LNM já era um recurso valorizado, agora a possibilidade de os próprios alunos criarem em sala (ou como dever de casa) traduções para vídeos torna-se uma atividade a mais à disposição, e com grandes vantagens em relação não só ao desenvolvimento de todas as cinco habilidades, como à atenção necessária a aspectos sócio-pragmáticos envolvidos na cena a ser traduzida. Atualmente, 
a multiplicação de programas de computador (e.g. VisualSubSync, Subtitle Workshop, Aegisub etc.) voltados especificamente para esse tipo de tradução com interfaces "amigáveis" (isto é, que podem ser utilizadas com facilidade por leigos) vem facilitar enormemente sua aplicação didática, garantindo que a tarefa será mais fácil e prazerosa.

Além disso, como afirma Santos (2009, p. 19), o aprendizado socialmente construído aliado ao exercício da habilidade tradutória favorecem o desenvolvimento da autonomia do aprendiz de LE e podem torná-lo mais autoconfiante, ampliando seu conhecimento sobre as línguas de trabalho (LM e LE), o que inclui a utilização gramatical, a escolha e a ampliação vocabular, as estratégias de aprendizagem, bem como a noção de adequabilidade de sua produção tanto oral quanto escrita.

\section{Considerações finais}

Neste artigo, procurou-se defender o uso da tradução pedagógica nas aulas de LNM. Por um lado, para um retorno bem-sucedido da tradução pedagógica às salas de aula, é preciso entender-se uma "língua" como um sistema de valores complexo, dinâmico, aberto e heterogêneo, totalmente imbricado com formações ideológicas e circunstâncias históricas, razão pela qual uma "tradução" só pode ser compreendida como uma "transformação regulada". Ou seja, para um texto não há nunca uma única solução tradutória correta, mas sim diferentes escolhas tradutórias possíveis conforme opte seu tradutor.

Por outro lado, a ideia de uma "condição pós-método" veio apoiar o uso de diferentes técnicas, métodos e abordagens de ensino-aprendizagem nas salas de aula, conforme as necessidades e interesses de alunos e professores. Assim, há de se perceber que para muitos a adoção de exercícios de tradução, em seus vários formatos, pode ser a melhor opção nas aulas de LNM. Por essa razão, defende-se aqui que a tradução deva ser tida como uma quinta habilidade a ser almejada no ensino-aprendizagem de LNM, uma vez que atende a situações recorrentes na vida social fora das salas de aula.

Com isso em mente, procurou-se rever algumas possibilidades de utilização pedagógica da tradução nas salas de aula. Acreditamos que, por ser acompanhada de uma leitura mais atenta que o comum por parte do estudante-tradutor, a tradução proporciona uma oportunidade de interpretação e crítica aprofundadas do texto-fonte, de 
seu contexto e, naturalmente, das características linguísticas de ambas as línguas envolvidas no processo tradutório, de modo que acredito que seu uso só tem a contribuir para o processo de ensino-aprendizagem de LNM. Com isso, não pretendo afirmar que aprender traduzindo seja o melhor método, e sim que não vejo revezes no uso da tradução pedagógica como uma opção de exercício, se aliada a outros tipos de atividades ao longo do processo de ensino-aprendizagem.

Através dos exemplos e pesquisas trazidos, portanto, espera-se contribuir para a difusão da tradução pedagógica e aprofundamento de novas pesquisas, e ainda para a proposição de novos usos para mais essa ferramenta educativa. Trabalhos como o de Ridd (2009) e Pontes, Lima e Sousa \& Silva (2015) indicam como têm avançado pesquisas nesse sentido de reestabelecer o lugar da tradução pedagógica no ensinoaprendizagem de LNM, embora todos concordem que ainda há espaço para mais. Além disso, espera-se colaborar para o reconhecimento da tradução como uma quinta habilidade, cujo desenvolvimento também é fundamental para uma vida plurilíngue completa.

\section{REFERÊNCIAS}

ALLWRIGHT, Dick. A morte do método. Tradução e post-scriptum de Silma Carneiro Pompeu. Texto originalmente publicado em 1991. Revista Horizontes de Linguística Aplicada, Brasília-DF, ano 2, n. 2, p. 21-29, dez. 2003.

ATKINSON, David. Teaching monolingual classes. Essex: Longman, 1993.

BENSON, Malcolm. Double translation. Humanising Language Teaching, ano 2, n. 2, mar. 2000. An old exercise.

BROWN, H. Douglas. Teaching by principles: an interactive approach to language pedagogy. New Jersey: Prentice Hall Regents, 1994.

DEPAULA, Lillian. Tradução, fonte para o ensino. In: DEPAULA, Lillian (org.). Tradução: uma fonte para o ensino. Vitória: EDUFES, 2007.

DUFF, Alan. Translation. Oxford: Oxford University, 1994.

FROTA, Maria Paula. A singularidade na escrita tradutora: linguagem e subjetividade nos estudos da tradução, na linguística e na psicanálise. Campinas (SP): Pontes; Fapesp, 2000. 
KLEIN-BRALEY, Christine; FRANKLIN, Peter. "The foreigner in the refrigerator": remarks about teaching translation to university students of foreign languages. In: MALMKJAER, Kirsten (ed.). Translation and language teaching, Manchester: St. Jerome , 1998. p. 53-62

KOBAYASHI, Hiroe; RINNERT, Carol. Effects of first language on second language writing: translation versus direct composition. Language learning, v. 42, n. 2, p. 183215, June 1992.

KOBAYASHI, Hiroe; RINNERT, Carol. L1/L2/L3 text construction by multicompetent writers. In: APPLIED LINGUISTICS ASSOCIATION OF AUSTRALIA NATIONAL CONFERENCE, 2012. Refereed proceedings... Perth (Australia): Curtin University, nov. 2012.

KOBAYASHI, Hiroe; RINNERT, Carol. Transferability of L1/L2 writing competence. In STOKE, Alan M. (ed.). JALT 2008 Conference Proceedings. Tokyo: JALT, 2009.

KUMARAVADIVELU, B. The postmethod condition: (e)merging strategies for second/foreign language teaching. TESOL Quarterly, v. 28, n. 1, p. 27-48, spring, 1994.

LAVAULT, Elisabeth. Fonctions de la traduction en didactique des langues: apprendre une langue en apprenant à traduire. Paris: Didier Érudition, 1985.

LIBERATTI, Elisângela. A tradução na sala de aula de LE: (des)construindo conceitos. Entrepalavras, Fortaleza, ano 2, v. 2, n. 1, p. 175-187, jan./jul. 2012.

NAIMUSHIN, Boris. Translation in foreign language teaching: the fifth skill. Modern English Teacher, v. 11, n. 4, 2002.

PETROVA, Galina. O ensino de Português-Língua Estrangeira no contexto tipologicamente distinto. Revista electrónica da Associação de Professores de Português, n. 2, 2001.

PONTES, Valdecy Oliveira; LIMA E SOUSA, Bill Bob A. A.; SILVA, Rafael Ferreira da. Tradução e ensino de língua estrangeira: uma agenda de pesquisa dos anos de 2004 a 2013. Cadernos de Tradução, v. 35, n. 2, p. 260-88, jul./dez. 2015.

PRABHU, N. S. There is no best method: why? TESOL Quarterly, v. 24, n. 2, p. 161176, sum. 1990.

RIDD, Mark David. Bibliografia de referência sobre tradução no ensino e aprendizagem de línguas. Revista Horizontes de Linguística Aplicada, Brasília-DF, v. 8, n. 2, 2009.

SAITO, Yoshifumi. Translation in English language teaching in Japan. KJEE, Tóquio, v. 3, 2012. 
SALIÉS, Tânia Gastão. Revisiting the role of L1 in L2 writing: perceptions of freshmen international students. In: OKTESOL CONFERENCE, 1995a. Annals... Oklahoma City, 1995a.

SALIÉS, Tânia Gastão. Revisiting the role of L1 in L2 writing: two case studies. Oklahoma State University. In: OKTESOL CONFERENCE, 1995b. Annals... Oklahoma City, 1995b.

SANTORO, Elisabetta. Tradução e ensino de línguas estrangeiras: confluências. Cadernos de Tradução, v. 1, n. 27, p. 147-60, 2011.

SANTOS JR., Elysio Soares. Em versão 2.0: desenvolvendo a autonomia do aprendiz e a habilidade tradutória por meio de atividades colaborativas na internet. Revista Desempenho, v. 10, n. 2, p. 3-24, dez. 2009.

SILVA, Yael Machado da. A tradução como instrumento no processo da aprendizagem de uma língua estrangeira. In: DEPAULA, Lillian (org.). Tradução: uma fonte para o ensino. Vitória: EDUFES, 2007.

SOUSA, Reijane Viana de. O uso de legenda oculta (closed caption) e a tradução de filmes: uma atividade prática, dinâmica e criativa. Revista Desempenho, Brasília-DF, ano 3, n. 3, 2004.

SOUZA CORREAA, Elisa Figueira de. A legendagem amadora dos 'fansubs' dentro dos Estudos da Tradução Audiovisual. In: 24 ENPULLCJ / 11 Congresso Internacional de Estudos Japoneses no Brasil, 2016, Manaus. Anais..., 2016.

SOUZA CORRÊA, Elisa Figueira de. A língua materna e a tradução no ensinoaprendizagem de língua não-materna: uma historiografia crítica. 2014. Tese (Doutorado em Letras) - Pontifícia Universidade Católica do Rio de Janeiro, Rio de Janeiro, 2014. cap. 2.

WELKER, Herbert A. Traduzir frases isoladas na aula de língua estrangeira: por que não? Horizontes de Linguística Aplicada, Brasília - DF, vol. 2, n. 2, p. 149-162, 2003.

\section{Como referenciar este artigo}

SOUZA CORRÊA, Elisa Figueira de. A tradução pedagógica: experimentos e exercícios para uso em aula. Rev. EntreLínguas, Araraquara, v. 3, n. 1, p. 179-202, jul./dez. 2017. Disponível em: <https://doi.org/10.29051/rel.v3.n2.2017.9225>. E-ISSN: 2447-3529.

Submetido em: 11/01/2017

Revisões requeridas: 17/02/2017

Aprovado em: 31/03/2017 